\title{
Impact of Patent Infringement Compensation Rules on Patent Quality Problems
}

\author{
Liang Dong $\mathbb{D}^{1}$ and Helin Pan $\mathbb{D}^{2}$ \\ ${ }^{1}$ Business School, Shaoxing University, Shaoxing 312000, China \\ ${ }^{2}$ Research Institute of Digital Economy, Zhongnan University of Economics and Law, Wuhan 430073, China \\ Correspondence should be addressed to Helin Pan; gxczphl@126.com
}

Received 20 February 2021; Revised 30 March 2021; Accepted 7 April 2021; Published 21 April 2021

Academic Editor: Lei Xie

Copyright (c) 2021 Liang Dong and Helin Pan. This is an open access article distributed under the Creative Commons Attribution License, which permits unrestricted use, distribution, and reproduction in any medium, provided the original work is properly cited.

\begin{abstract}
Compensation rules for patent infringement greatly affect patent quality, which is closely related to R\&D investments. In this study, A duopoly game model was developed to analyze innovative factories' R\&D investment and patent licensing behavior, as well as the strategic choices of potential infringers under different compensation rules for patent infringement. Furthermore, a comparative analysis was conducted to analyze the patent quality under different scenarios, ultimately finalizing an optimal sequence rule for patent infringement compensation. The results show that patent quality is influenced by the invention height of patent and R\&D efficiency, while the amount of patent infringement compensation has a great effect on potential infringement behavior. Patent quality can be effectively improved if the court adopts a proper sequence rule for patent infringement compensation according to the market circumstances.
\end{abstract}

\section{Introduction}

The patent for "Slide to Unlock" of Apple Inc. affords much food for thought. In 2014, a court jury in San Jose, California, convicted Samsung of infringing the patent of Apple Inc. for "Slide to Unlock" and "Fast Link," asking Samsung to pay $\$ 119.6$ million to Apple Inc. as a compensation. In February 2016, the U.S. Circuit Court ruled that Apple's patent for "Slide to Unlock" was invalid because "Apple's so-called patented technology had appeared in an earlier technology patent." However, in October 2016, the U.S. Federal Circuit Court overturned the previous judgment and again ruled that Samsung had infringed Apple's patent. The judge decided that the patent for "Slide to Unlock" belonged to Apple. However, the attitudes toward this patent problem are different between different countries, e.g., the German and British courts declared the patent void.

As can be seen from this suspenseful case, the patent right, which has been regarded as a clearly defined property right for a long time, is not absolutely reliable and the validity is worthy of deep discussions (Jeon [1] integrated a series of events regarding patent infringement; it shows that roughly a half of litigated patents are found to be invalid). In recent years, some scholars have conducted a detailed analysis on the validity of patent rights, pointing out that the right property which has been clearly defined previously in practice is sometimes ambiguous; i.e., it is unclear whether the rights of a patent owner, after announcing to the public his/her ownership of a certain patent and obtaining the exclusive rights therein, exist in practice, Furthermore the scope of questionable patent is also unclear. These patents can be classified as questionable patents (patent review is in itself a process with strong subjective judgment because the patent examiner's personal knowledge has a great effect on the review results; more often than not, the patent examiner has an unclear understanding of the patented elements, so it is not at all surprising that the patent boundary is fuzzy).

Questionable patents are also called weak patents or probabilistic patents $[2,3]$. In 2003, the U.S. Federal Trade Commission first proposed the concept of a "questionable patent" in Promoting Innovation: An Appropriate Balance between Competition and Patent Laws and Policies. A 
"questionable patent" is one that does not meet the patent licensing requirements or one that has an excessively wide scope of claims [4]. In recent years, due to the increasing complexity and diversity of inventions and creations, the number of questionable patents has increased rapidly, seriously affecting the normal operation of patent systems. This causes harm to legitimate competition and disrupts the social order of economic development (neem tree is a resource of great cultural significance in India; Indian farmers usually use the juice of neem tree seeds as a natural insecticide; in the early 1990s, researchers at W. R. Grace Company discovered a way to stabilize and activate azadirachtin and applied for a patent for this method; so far, Indian farmers have discovered that they are required to pay high user fees to use the resources they have depended on for generations; Grace Company took the lead in planting plants in India and continued to expand the market share of neembased products [5]). Moreover, the innovation patent thicket may therefore be hindered. A large number of questionable patents have led to uncertainty in innovation revenue (Cohen et al. [6] provided the first large-sample evidence on the behavior and impact of nonpracticing entities (NPEs) in the intellectual property space; they found that NPE litigation had a real negative impact on innovation at targeted firms: firms' substantially reduced their innovative activity after settling with NPEs), thus weakening the motivating effect of the patent system on innovation.

The root cause for the presence of questionable patents is that the patent is not an enforceable right, and that the validity of the patent is often difficult to assess [7]. Other reasons include careless patent examination, the rapid increase of the number of patent applications, abuse of patent application right with the present system defects, and uncertain patient validity and defects in the governmental patent funding policies [8].

"Questionable patents" have aroused great attention from scholars, most of whom have explored the causes of "questionable patents" and put forward relevant countermeasures. Choi points out that owing to the lack of a rigorous examination process, many patent applications of questionable value have been approved, generally suppressing innovation rather than promoting innovation [9]. Considering that questionable patent holders lack the motivation to innovate, it is imperative to reform the patent system, strengthen third-party supervision, and replace expensive, time-consuming patent litigation with post-grant patent examination. Lemley and Shapiro [2] argue that the patent right is uncertain, while the patent system allows the patentee to hold the exclusive monopoly right for a certain period. Resources should be allocated for patent applications of greater commercial value in order to resolve the uncertainty of patent value.

In terms of the form, the presence of a "questionable patent" is defined as patent that is examined in a relaxed manner. However, in practice, the problem is caused by the inherent defects of patent systems. Some speculators take advantage of these defects to abuse the patent right. In fact, the patent right is not a natural right, but a legal right, which should be used judiciously. Farrell and Shapiro [10] argued that a "questionable patent" is caused by the relevant court's failure to fully examine the validity of the patent. In their game theory model, they proved that determining patent validity before patent granting is beneficial to social welfare. The impact of questionable patents on market entities depends largely on patent granting. Their presence may cause costly litigation and even hinder patent innovation. Inspired by the model built by Farrell and Shapiro, Encaonu and Lefouili [11] expressed a new view on questionable patents. On the one hand, they argued that a questionable patent may not necessarily involve small or micro innovations, while disruptive innovations may also lead to the presence of questionable patents; on the other hand, they ignored the hypothesis that the license contract provided by the patent owner must be accepted by all downstream vendors. They believed that questionable patents may be generated due to insufficient innovations or ambiguity in novelty. In addition, the presence of questionable patents is inevitable, so judicial departments should strengthen their supervision over questionable patents. Schuett [12] pointed out that a patent examiner's salary generally depends on the number of the patents examined by him/her; because he/she can save much more time when they pass a patent application than when they reject the application, patent examiners are more willing to grant a patent. This is also an important factor in the decline of patent quality. Kwon [13] proposed a new method to identify weak patents by using patent citation information in conjunction with the textual similarity between citing and cited patents. This method shows that $13 \%$ of U.S. patents filed from 2001 to 2010 are weak patents. He suggests that patent owners have an incentive to invest in maintaining and appropriating weak patents, and thus the current patent system is incapable of self-correcting weak patent issues.

Teece et al. [14] argued that because questionable patents have seriously affected the normal operation of the patent system, the reform of the patent system should focus on improving patent quality to facilitate innovations and highquality inventions. Questionable patents have seriously affected patent quality. Love [15] pointed out that even though the patent offices have tried their best to improve the examination process, questionable patents still emerge in an endless stream. In this regard, expenses can be adjusted to reduce the number of patents granted, i.e., it is necessary to raise the maintenance cost of patents and cut down the cost of application for post-granting administrative proceedings. Lei and Wright [16] argued that the emergence of questionable patents is due to the lack of examination of patent applications. In other words, patent examiners ignore the objective validity of patents. Questionable patents have raised litigation-related social costs and reduced the social benefits of innovation incentives. Choi and Gerlach [17] analyzed patent pools and their effects on litigation incentives, overall royalty rates, and social welfare when patent rights are probabilistic and can be invalidated in court. The results show that patent pools with complementary patents reduce social welfare as they charge higher licensing fees and chilled subsequent innovation incentives if patents are sufficiently weak. 
The above findings are concerned with the causes of questionable patents and their impact on innovation incentives. Most scholars believe that the number of questionable patents should be reduced by strengthening the examination process, increasing patent subsidies, and improving the patent system. However, most scholars do not consider the effects of patent infringement compensation rules on patent quality (the patent quality mentioned in this paper is an index parameter used to measure "questionable patents"; it represents the probability that a patent is deemed valid by the court after a patent litigation occurs). When patent infringement occurs, the court generally adopts the following two rules to cope with the act of infringement:

(1) Profit Loss Rule. This rule requires that the infringer should return the profit which originally belonged to the infringed to the infringed party as if infringement had not occurred (in this situation, the patent owner builds a factory independently and makes monopoly profits or licenses the patent to others), so that the infringed could gain the same profit as that prior to infringement.

(2) Unjustified Enrichment Rule. This rule requires that the infringer should return all profit obtained in its infringement act to the infringed.

As can be seen from the previous discussions, these two rules differ from each other in terms of operating mechanisms. The goal of the profit loss rule is to compensate the infringed for the loss of profit caused by infringement, while the goal of the unjustified enrichment rule is to prohibit the infringer from gaining profit in its act of infringement. The different ways adopted by the court in handling patent infringement may influence the interests of patent holders and potential infringer (Mazzeo et al. [18] used 340 patent infringement cases from 1995 to 2008 as a research sample and conducted a standardized study on related data; the results show that factors such as the calculation method of the compensation and the characteristics of the patent have a significant impact on the patent infringement damages), thereby affecting the behaviors of various market participants. As such, patent infringement compensation rules have an important effect on patent quality (Pincus [19] points out that after an infringement act is affirmed, the mechanism and calculation method by which the intellectual property holder obtains indemnity are important for giving full play to the role of the intellectual property protection system in remedying the intellectual property, stimulating knowledge innovation, and promoting economic development).

In this study, game theory has been adopted as the main research method to analyze the market behaviors of innovative firms and potential infringers from the perspective of endogenous patent quality. The effects of different patent infringement compensation rules on the market outcome are then analyzed. The following two issues are primarily discussed in this paper. On the one hand, what are the differences with respect to the effects of different patent infringement compensation rules on market outcome in terms of innovation incentives and potential infringers' behavior? What are the differences in patent quality and social welfare under different rules? On the other hand, can the patent system be further optimized? Specifically, because different patent infringement compensation rules have different effects on market participants, the patent quality under different rules must be different. Is it therefore possible to find a patent infringement compensation sequence rule that is best for patent quality (in international judicial practice, different countries have preference for different calculation methods; for example, the plaintiffs in the United States and the United Kingdom prefer the "profit loss rule," while the plaintiffs in Germany prefer the "unjust enrichment rule"; however, Japan is in the midst of changes, with the "profit loss rule" becoming increasingly popular; on 7 June 2019, the Grand Panel of the Intellectual Property High Court of Japan set a flexible and pro-patentee approach in determining patent infringement damages which may result in higher damage awards, assuming the criteria are satisfied; the prospect of Japanese courts being able to award higher patent infringement damage awards in the future using the calculation rules outlined in this milestone decision will contribute to the greater protection of patent rights in Japan [20]) ?

The research contribution of this paper lies in the introduction of the concept (to a certain extent, "questionable patents" have played an indispensable role in technological development; patent granting requires a certain innovation height, but since technological development is always progressive, the development of any new development must be based on the existing technology; to take out a patent for an invention, it must be "novel," "practical," and "non-obvious"; the innovation height is a comprehensive concept that includes the above three elements; a "questionable patent" is not one that is stale, but one that has an insufficient innovation height; for example, in the pharmaceutical industry, a new drug usually has to go through two processes, i.e., drug design and drug testing, before it is patented; although drug design may be completed early in many cases, drug testing generally takes ten years or several decades and needs hundreds of millions of dollars; from the perspective of patent examination, the completion of drug design can only indicate that the drug is "novel" and "non-obvious," but its "practicality" has not been proven, yet, so the drug cannot be patented owing to its insufficient innovation height; the "practicality" of this drug cannot be recognized unless more investment is made for drug testing to prove the drug is indeed effective; only then can this drug be considered to have a sufficient innovation height and patented) of "innovation height" to build an endogenous model of patent quality. Generally speaking, the higher the R\&D investment is, the higher the invention height is. Moreover, higher invention height means higher patent quality. Thus, there exists a positive correlation between R\&D investment and patent quality. If $R \& D$ investment is regarded as an exogenous variable, the invention height can be transformed into an endogenous variable to make patent quality endogenous. On this basis, we can further analyze the specific amount of compensation and its effects on innovative firms' behavior 
and patent quality under different patent infringement compensation mechanisms.

\section{Model Assumption}

We consider a Cournot duopoly competition model composed of Firm I and Firm E, which is similar to [21]. We assume that both firms produce a certain product at the same marginal cost $c(c<1)$. The inverse demand function for this product is $p=1-\left(q^{I}+q^{E}\right)$. Suppose Firm I improves its production technology by means of R\&D investment and has taken out a patent for the technology, thus decreasing the marginal cost of this product by $\Delta c$ (for example, in the process of oil refining, one of the main steps is to remove phospholipids and free fatty acid from the crude oil; traditionally, the hydration and alkali refining technology is used to execute this step, but the method is time-consuming and costly; later, some researchers developed a powdery reagent with strong physical adsorption; added to the crude oil, the reagent can remove phosphorus and acid in a short time, thereby greatly reducing the oil refining cost; this technology has been patented; actually, other researchers had developed a similar product before this reagent appeared; however, the product failed to be patented because of the non-obvious effect, i.e., insufficient innovation height), which represents invention height. Suppose Firm I's $\mathrm{R} \& \mathrm{D}$ investment is $k=\theta \Delta c^{2}$, where $\theta$ represents the $\mathrm{R} \& \mathrm{D}$ efficiency. The higher $\theta$ is, the lower the R\&D efficiency is and the higher the R\&D investment is; conversely, the lower $\theta$ is, the lower the R\&D investment is, suggesting that Firm I has relatively higher R\&D efficiency.

Although Firm I has taken out a patent for the new technology, the patent may not be effective. Suppose its patent quality is $\rho \in[0,1]$, where $\rho$ also represents the probability of winning a patent infringement lawsuit for Firm I. In this paper, it is assumed that $\rho=\Delta c / \bar{c}$, where $\bar{c}$ represents significant invention height. To simplify the analysis, it is assumed that $\bar{c}=c$ in this paper. In other words, when Firm I's new technology reduces the marginal cost to zero, its patent must be effective.

The game in this paper consists of three stages, as shown in Figure 1. During the first stage, Firm I determines its R\&D investment scale and patent license contract $[r, F]$, where $r$ represents output commission and $F$ represents a fixed fee.

During the second stage, Firm E decides whether to accept a patent license contract from Firm I. This results in one of the following three situations:

(i) Situation A: Firm E does not accept the patent license contract from Firm I and still uses the old production technology.

(ii) Situation B: Firm E accepts the patent license contract from Firm I and uses the new production technology.

(iii) Situation C: Firm E does not accept the patent license contract from Firm I but uses the new production technology by means of infringement. At this time, Firm I will file a lawsuit, and the probability of winning the lawsuit is $\rho$. If Firm I wins the lawsuit, Firm E will need to compensate Firm I for its loss. Otherwise, Firm E will not need to pay any fees if it wins the lawsuit.

The unjustified enrichment rule or profit loss rule is adopted for determining the amount of compensation for patent infringement. Under the unjust enrichment rule, if Firm I wins the lawsuit, then Firm E must transfer all the illegal profits to Firm I, such that Firm E's final profit becomes zero. Under the profit loss rule, Firm E should compensate Firm I for its actual loss, so that Firm I's final profit is the same as its due profit. Because both situation A and B can be regarded as equilibrium situations that "should have occurred" under the assumption of this paper, these two situations will be discussed separately.

At the third stage, either firm obtains its own benefits according to the previously selected strategy.

\section{Analysis of Market Equilibrium in a Non- Infringement Situation}

According to the assumption of this paper, Firm E will not infringe in situation A or situation B. The backward induction method in [21] will be used to analyze Firm I's R\&D investment decision and either firm's profit gained in situation A and situation B. Specifically speaking, the firm's optimal pricing and profit are calculated first under the premise of a given invention height. Then, the optimal R\&D investment level is determined for the innovative firm according to its $\mathrm{R} \& \mathrm{D}$ investment function while determining patent quality.

3.1. Situation A: Firm I Adopts New Technology, while Firm E Continues to Use the Old Production Technology. First, the final stage of the game is analyzed. At this time, Firm I's R\&D investment has been completed, so the invention height has been determined, as well. Therefore, the profit function for either firm in situation $\mathrm{A}$ is as follows:

$$
\left\{\begin{array}{l}
\pi^{\mathrm{AI}}=\left[1-\left(q^{\mathrm{AI}}+q^{\mathrm{AE}}\right)-c+\Delta c^{A}\right] q^{\mathrm{AI}}-k^{A}, \\
\pi^{\mathrm{AE}}=\left[1-\left(q^{\mathrm{AI}}+q^{\mathrm{AE}}\right)-c\right] q^{\mathrm{AE}} .
\end{array}\right.
$$

According to the conditions for profit maximization, either firm's profit can be revealed under the premise of undetermined innovation height by taking the first-order optimal conditions of $q^{\mathrm{AI}}$ and $q^{\mathrm{AE}}$ for $\pi^{\mathrm{AI}}$ and $\pi^{\mathrm{AE}}$, respectively:

$$
\left\{\begin{array}{l}
\pi^{\mathrm{AI} *}=\frac{(1-c+2 \Delta c)^{2}}{9}-k, \\
\pi^{\mathrm{AE} *}=\frac{(1-c-\Delta c)^{2}}{9} .
\end{array}\right.
$$

In situation $\mathrm{A}$, since Firm $\mathrm{E}$ does not use the patented technology of Firm I, the second stage of the game needs not be analyzed. The first stage still needs to be analyzed though, i.e., Firm I's R\&D investment decision needs to be analyzed. 


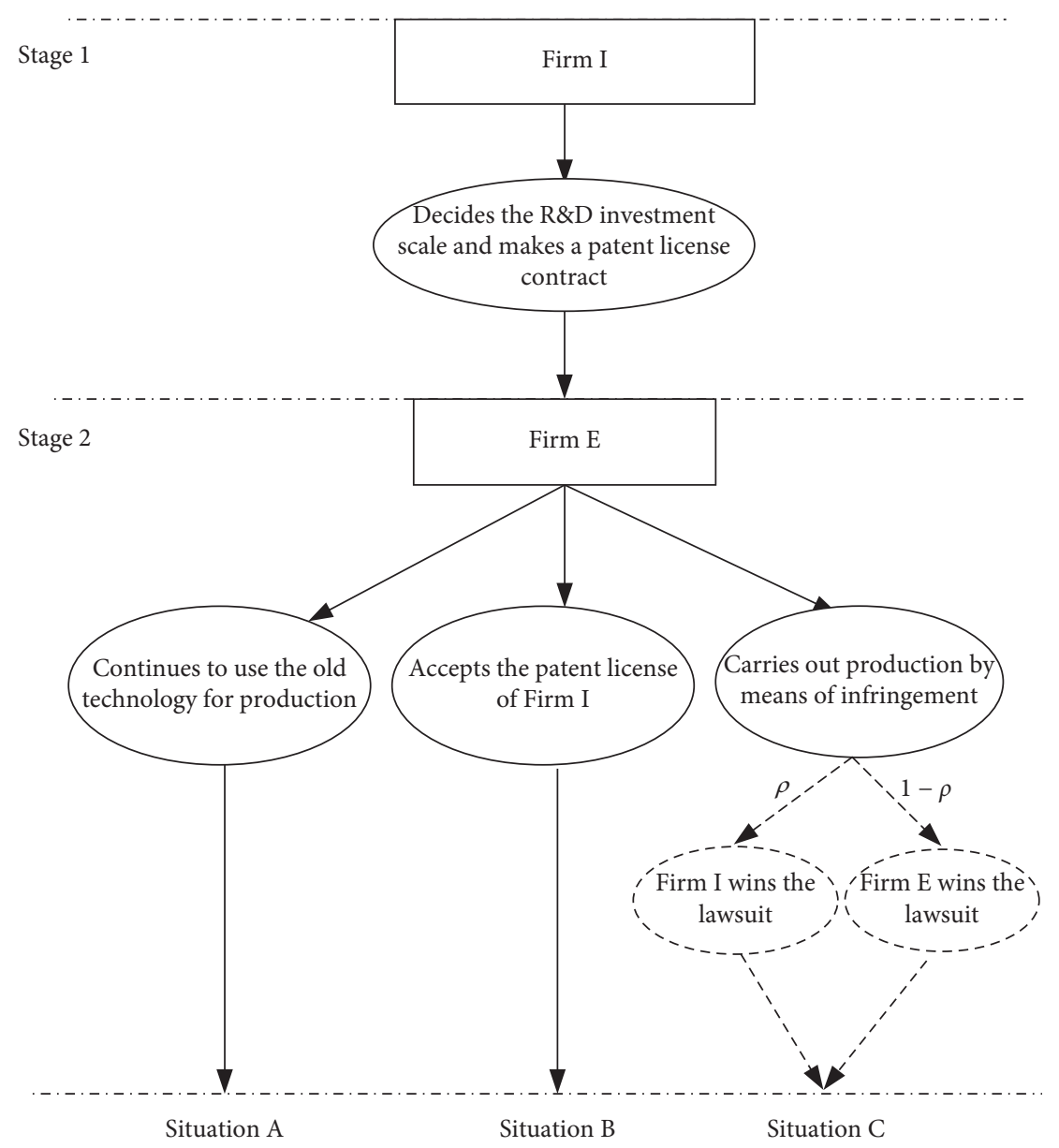

FIgURE 1: Game tree.

By substituting $k=\theta \Delta c^{2}$ into equation (2), we derive an objective function for Firm I in situation A, as follows:

$$
\underset{\Delta c}{\operatorname{Max}} \pi_{R \& D}^{\mathrm{AI} *}=\frac{(1-c+2 \Delta c)^{2}}{9}-\theta \Delta c^{2} .
$$

The first-order optimal condition of $\Delta c$ is taken for equation (3), revealing the optimal invention height of Firm $\mathrm{I}$ in situation $\mathrm{A}$, as follows:

$$
\Delta c^{A *}= \begin{cases}c, & \text { if } \theta \leq \frac{(2+2 c)}{9 c}, \\ \frac{2(1-c)}{9 \theta-4}, & \text { if } \theta>\frac{(2+2 c)}{9 c} .\end{cases}
$$

Equation (4) shows that when $\theta \leq(2+2 c) / 9 c$, i.e., when is low, the R\&D efficiency in the market is high. Moreover, Firm I's profit increases with its increase in R\&D investment. Therefore, the optimal choice is to increase the innovation height to the highest level. At this time, Firm I is bound to provide a full-quality patent. Conversely, when $\theta>(2+2 c) / 9 c$, owing to the low R\&D efficiency in the market, it may be difficult to obtain satisfactory results with higher R\&D investment. As such, Firm I may not invest enough R\&D funds. As a result, its innovation is turned into a "questionable patent." With the innovation height being determined, either firm's optimal output can be identified by combining equation (2) with equation (4), as shown by equation (5) below:

$$
\begin{aligned}
& q^{\mathrm{AI} *}= \begin{cases}\frac{1+c}{3}, & \text { if } \theta \leq \frac{2+2 c}{9 c}, \\
\frac{3 \theta(1-c)}{9 \theta-4}, & \text { if } \theta>\frac{2+2 c}{9 c}\end{cases} \\
& q^{\mathrm{AE} *}= \begin{cases}\frac{1-2 c}{3}, & \text { if } \theta \leq \frac{2+2 c}{9 c}, \\
\frac{(1-c)(3 \theta-2)}{9 \theta-4}, & \text { if } \theta>\frac{2+2 c}{9 c} .\end{cases}
\end{aligned}
$$

Based on the above analysis, either firms' profit (considering that either firm's output can never be negative, as can be seen from equation (6), when $\theta \leq(2+2 c) / 9 c$, if $c \geq 1 / 2$, then $q^{\mathrm{AE} * *}=0$; if $c>1 / 2$, then $q^{\mathrm{AE} * *}>0$; when $\theta>(2+2 c) / 9 c$, if $\theta \leq 2 / 3$, then $q^{\mathrm{AE} * *}=0$; if $\theta>2 / 3$, then $\left.q^{\mathrm{AE} * *}>0\right)$ in situation A can be revealed, as shown in Table 1.

Proposition 1 can be put forward as follows based on the above analysis. 
TABle 1: Profits of firms in situation A.

\begin{tabular}{lcc}
\hline Profit & $c<1 / 2$ & $c \geq 1 / 2$ \\
$\pi_{R \& D}^{\mathrm{AI} *}(\theta \leq 2+2 c / 9 c)$ & $(1+c)^{2} / 9-\theta c^{2}$ & $1 / 4-\theta c^{2}$ \\
$\pi_{R \& D}^{\mathrm{AI} *}(\theta>2+2 c / 9 c)$ & $(1-c)^{2} \theta / 9 \theta-4$ & $(1-c)^{2} \theta / 9 \theta-4$ \\
$\pi^{\mathrm{AE*}}(\theta \leq \max \{2 / 3,2+2 c / 9 c\})$ & $(1-2 c)^{2} / 9$ & 0 \\
$\pi^{\mathrm{AE*}}(\theta>\max \{2 / 3,2+2 c / 9 c\})$ & $(2-3 \theta)^{2}(1-c)^{2} /(9 \theta-4)^{2}$ & $(2-3 \theta)^{2}(1-c)^{2} /(9 \theta-4)^{2}$ \\
\hline
\end{tabular}

Proposition 1. When Firm I uses the new technology while Firm E continues to use the old production technology, Firm I will provide a full-quality patent under the condition of high R\&D efficiency, i.e., $\theta \leq(2+2 c) / 9 c$; Firm I will provide a questionable patent under the condition of low R\&D efficiency, i.e., $\theta>(2+2 c) / 9 c$; if the R\&D efficiency and marginal cost are both high, Firm E may be eliminated from the market.

3.2. Situation B: Firm I Allows Firm E to Use the Patented Technology, and Both Firms Use the New Production Technology. Suppose Firm I provides a two-part patent license contract $[r, F]$, where $r$ represents output commission and $F$ represents a fixed fee. If Firm E accepts the contract, the duopoly firms' profit functions are shown as

$$
\left\{\begin{array}{l}
\pi^{\mathrm{BI}}=\left[1-\left(q^{\mathrm{BI}}+q^{\mathrm{BE}}\right)-c+\Delta c^{B}\right] q^{\mathrm{BI}}+r q^{\mathrm{BE}}+F, \\
\pi^{\mathrm{BE}}=\left[1-\left(q^{\mathrm{BI}}+q^{\mathrm{BE}}\right)-c+\Delta c^{B}\right] q^{\mathrm{BE}}-r q^{\mathrm{BE}}-F .
\end{array}\right.
$$

According to the conditions for profit maximization, the first-order optimal conditions of $q^{\mathrm{BI}}$ and $q^{\mathrm{BE}}$ are taken as $\pi^{\mathrm{BI}}$ and $\pi^{\mathrm{BE}}$,respectively, revealing either firm's profit under the premise of undetermined innovation height, as follows:

$$
\left\{\begin{array}{l}
q^{\mathrm{BI} *}=\left(1-c+r+\Delta c^{B}\right) / 3 \\
q^{\mathrm{BE} *}=\left(1-c-2 r+\Delta c^{B}\right) / 3
\end{array}\right.
$$

When drafting a patent license contract, Firm I is bound to give priority to its own profit, but it should be noted that Firm E's profit is higher than Firm I's profit in situation A. Otherwise, Firm E will lose the economic value of using the patent. Firm I's R\&D investment cost is also analyzed. By substituting equation (8) into equation (7), we derive an objective function for Firm $\mathrm{E}$ in situation $\mathrm{B}$, as follows:

$$
\begin{aligned}
& \qquad \pi^{\mathrm{BI} *}=\frac{c^{2}-5 r^{2}+5 r\left(1+\Delta c^{B}\right)+\left(1+\Delta c^{B}\right)^{2}-\left(2+5 r+2 \Delta c^{B}\right) c}{9}+F \\
& \text { s.t. } \pi^{\mathrm{BE} *} \geq \pi^{\mathrm{AE} * *} .
\end{aligned}
$$

An optimal patent license contract can be developed for Firm I by taking the first-order condition of $r$ for $\pi^{\mathrm{BI}}$ in equation (9), as follows:

$$
\left\{\begin{array}{l}
r^{*}=\frac{\left(1-c+\Delta c^{B}\right)}{2} \\
F^{*}=-\pi^{\mathrm{AE} *}
\end{array}\right.
$$

Now, by substituting equation (10) into equation (8), we obtain $q^{\mathrm{BE} *}=0$ and $q^{\mathrm{BI} *}=r$. This shows that Firm I's optimal patent license contract must contain a very high patent output commission, but Firm E's output is decreased to zero. In addition, Firm I also needs to pay a fixed fee for patent licensing to Firm E. The fee is equal to Firm E's profit gained in situation A, so this shows that Firm I wants to expel Firm E from the market in order to monopolize the entire market (in reality, this phenomenon manifests itself in an advanced firm's acquisition or merger of a backward firm, e.g., Google's acquisition of Motorola, Microsoft's acquisition of Nokia, and so on). Situation B is a perfect monopoly market, while situation
A is a duopoly market with certain competition. Therefore, the two firms' joint profit in situation A must be lower than that in situation B. According to the above analysis, Firm E has the same profit in situations A and B, so Firm I's profit in situation $A$ is lower than that in situation $\mathrm{B}$.

Using the same analysis process as situation A, it is easy to find the optimal invention height of Firm I in situation B, as shown in equation (11) below:

$$
\Delta c^{B *}= \begin{cases}c, & \text { if } \theta \leq \frac{1}{4 c} \\ \frac{1-c}{4 \theta-1}, & \text { if } \theta>\frac{1}{4 c}\end{cases}
$$

Proposition 2 can be put forward based on the above analysis. Firm I's revenue in situation $B$ can be revealed by combining (9), (10), and (11) together, as shown in equation (12) (since firm E's profit in situation B is the same as that in situation $\mathrm{A}$, we will not give unnecessary details anymore here): 


$$
\pi_{R \& D}^{\mathrm{BI} *}= \begin{cases}\frac{1}{4}-\theta c^{2}-\pi^{\mathrm{AE} * *}, & \text { if } \theta \leq \frac{1}{4 c}, \\ \frac{\theta(1-c)^{2}}{4 \theta-1}-\pi^{\mathrm{AE} * *}, & \text { if } \theta>\frac{1}{4 c} .\end{cases}
$$

Proposition 2. When Firm I uses the new technology and Firm E accepts the patent license contract, Firm I will provide a full-quality patent as long as the R\&D efficiency is high, i.e., $\theta \leq 1 / 4 c$; Firm I will provide a "questionable patent" if the $R \& D$ efficiency is low, i.e., $\theta>1 / 4 c$. Firm I's optimal patent license contract must contain a high output commission, and it is bound to receive a negative fixed patent royalty from Firm
$E$, thereby causing manufacturer $E$ to withdraw from the market, while Firm I will monopolize the entire market. Firm I's final profit is not less than its profit gained in situation A.

\section{Analysis of Market Equilibrium in an Infringement Situation}

4.1. Analysis of Market Equilibrium under the Unjust Enrichment Rule. At the last stage of the game, because the $R \& D$ cost has already incurred at the previous stage, there is only a sunk cost at the present stage, so Firm I does not consider the cost. Now, the two firms' expected profits are shown in the following equation:

$$
\left\{\begin{array}{l}
E\left(\pi_{\mathrm{UE}}^{\mathrm{CI}}\right)=\left[1-\left(q_{\mathrm{UE}}^{\mathrm{CI}}+q_{\mathrm{UE}}^{\mathrm{CE}}\right)-c+\Delta c_{\mathrm{UE}}^{C}\right] q_{\mathrm{UE}}^{\mathrm{CI}}+\rho_{\mathrm{UE}}^{\mathrm{C}}\left[1-\left(q_{\mathrm{UE}}^{\mathrm{CI}}+q_{\mathrm{UE}}^{\mathrm{CE}}\right)-c+\Delta c_{\mathrm{UE}}^{C}\right] q_{\mathrm{UE}}^{\mathrm{CE}} \\
E\left(\pi_{\mathrm{UE}}^{\mathrm{CE}}\right)=\left(1-\rho_{\mathrm{UE}}^{\mathrm{C}}\right)\left[1-\left(q_{\mathrm{UE}}^{\mathrm{CI}}+q_{\mathrm{UE}}^{\mathrm{CE}}\right)-c+\Delta c_{\mathrm{UE}}^{C}\right] q_{\mathrm{UE}}^{\mathrm{CE}}
\end{array}\right.
$$

The first-order optimal conditions of $q_{\mathrm{UE}}^{\mathrm{CI}}$ and $q_{\mathrm{UE}}^{\mathrm{CE}}$ are taken for $E\left(\pi_{\mathrm{UE}}^{\mathrm{CI}}\right)$ and $E\left(\pi_{\mathrm{UE}}^{\mathrm{CE}}\right)$, deriving equation (14), as follows:

$$
\left\{\begin{array}{l}
q_{\mathrm{UE}}^{\mathrm{CI} *}=\frac{\left(1-c+\Delta c_{\mathrm{UE}}^{C}\right)\left(1-\rho_{\mathrm{UE}}^{C}\right)}{3-\rho_{\mathrm{UE}}^{C}}, \\
q_{\mathrm{UE}}^{\mathrm{CE} *}=\frac{1-c+\Delta c_{\mathrm{UE}}^{C}}{3-\rho_{\mathrm{UE}}^{C}} .
\end{array}\right.
$$

Either firm's optimal profit can be calculated by combining equation (13) with equation (14). A profit function can then be derived for Firm I at the first stage of the game, as shown in equation (15) below:

$$
\pi_{\mathrm{UE}}^{R \& D}=E\left(\pi_{\mathrm{UE}}^{\mathrm{CI}}\right)^{*}-k=\frac{\left(1-c+\Delta c_{\mathrm{UE}}^{C}\right)^{2}}{\left(3-\rho_{\mathrm{UE}}^{C}\right)^{2}}-\theta\left(\Delta c_{\mathrm{UE}}^{C}\right)^{2} .
$$

By substituting $\rho_{\mathrm{UE}}^{C}=\Delta c_{\mathrm{UE}}^{C} / c$ into the above equation and taking the first-order optimal condition of $\Delta c$ for $\pi_{\mathrm{UE}}^{R \& D}$, we can reveal Firm I's optimal R\&D investment level and then evaluate either firm's optimal profit and related market outcome. However, since the function is rather complicated, it is difficult to derive an intuitive form of expression for the optimal R\&D investment function. To simplify analysis, Firm I's optimal innovation height and patent quality, as well as either firm's profit and market price, are calculated at different levels of $c$ and $\theta$ based on a numerical example. For instance, given $c=0.2$ and $\theta=4, \rho_{\mathrm{UE}}^{C}=\Delta c_{\mathrm{UE}}^{C} / c=5 \Delta c_{\mathrm{UE}}^{C}$ can be obtained, substituting $\rho_{\mathrm{UE}}^{C}=5 \Delta c_{\mathrm{UE}}^{C}$ into equation (15) and taking the first-order optimal condition of $\Delta c_{\mathrm{UE}}^{\mathrm{C}}$ for $\pi_{\mathrm{UE}}^{\text {Cl.stage } 1}$. The optimal innovation height and patent quality of Firm $I$ can be derived as $\Delta c_{\mathrm{UE}}^{C^{*}}=0.05$ and $\rho_{\mathrm{UE}}^{C^{*}}=0.25$. We can derive $\pi_{\mathrm{UE}}^{\mathrm{CI} . s t a g e 1 *}=0.08, q_{\mathrm{UE}}^{\mathrm{CI}}=0.3, \quad$ and $\quad q_{\mathrm{UE}}^{\mathrm{CE}^{*}}=0.25$ from substituting $\Delta c_{\mathrm{UE}}^{C^{*}}, \rho_{\mathrm{UE}}^{\mathrm{C*}}$ into equations (14) and (15), respectively. Finally, substituting $\Delta c_{\mathrm{UE}}^{\mathrm{C}^{*}}, \rho_{\mathrm{UE}}^{\mathrm{C*}}, q_{\mathrm{UE}}^{\mathrm{CI} *}$, and $q_{\mathrm{UE}}^{\mathrm{CE} *}$ into equation (13), we can get $E\left(\pi_{\mathrm{UE}}^{\mathrm{CE}}\right)^{*}=0.063$. The results of other numerical calculation examples are shown in Table 2.

4.2. Analysis of Market Equilibrium under the Profit Loss Rule. Under the profit loss rule, the infringer must compensate the innovative firm for its loss of profit so that the latter's final profit should be the same as its due profit. Suppose Firm I's due profit is $R$ after the court judges its patent valid. As such, either firm's profit function is as follows:

$$
\left\{\begin{array}{l}
E\left(\pi_{\mathrm{LR}}^{\mathrm{CI}}\right)=\left(1-\rho_{\mathrm{LR}}^{\mathrm{C}}\right)\left[1-\left(q_{\mathrm{LR}}^{\mathrm{CI}}+q_{\mathrm{LR}}^{\mathrm{CE}}\right)-c+\Delta c_{\mathrm{LR}}^{\mathrm{C}}\right] q_{\mathrm{LR}}^{\mathrm{CI}}+\rho_{\mathrm{LR}}^{\mathrm{C}} R, \\
E\left(\pi_{\mathrm{LR}}^{\mathrm{CE}}\right)=\left[1-\left(q_{\mathrm{LR}}^{\mathrm{CI}}+q_{\mathrm{LR}}^{\mathrm{CE}}\right)-c+\Delta c_{\mathrm{LR}}^{\mathrm{C}}\right] q_{\mathrm{LR}}^{\mathrm{CE}}-\rho_{\mathrm{LR}}^{\mathrm{C}}\left[R-\left(1-\left(q_{\mathrm{LR}}^{\mathrm{CI}}+q_{\mathrm{LR}}^{\mathrm{CE}}\right)-c+\Delta c_{\mathrm{LR}}^{\mathrm{C}}\right) q_{\mathrm{LR}}^{\mathrm{CI}}\right] .
\end{array}\right.
$$

The first-order optimal conditions of $\mathrm{LR}$ and $\mathrm{CR}$ are taken as $E\left(\pi_{\mathrm{LR}}^{\mathrm{CI}}\right)$ and $E\left(\pi_{\mathrm{LR}}^{\mathrm{CE}}\right)$, respectively, revealing either firm's expected profit and market price, as shown in the equation below: 
TABLe 2: A numerical example of market equilibrium under the unjust enrichment rule.

\begin{tabular}{|c|c|c|c|c|c|c|c|c|}
\hline 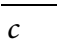 & $\theta$ & $\Delta c_{\mathrm{UE}}^{C^{*}}$ & $\rho_{\mathrm{UE}}^{C *}$ & $\pi_{\mathrm{UE}}^{\text {Cl.stage } 1}$ & $E\left(\pi_{\mathrm{UE}}^{\mathrm{CE}}\right)^{*}$ & $p_{\mathrm{UE}}^{\mathrm{C*}}$ & $q_{\mathrm{UE}}^{\mathrm{CI} *}$ & $q_{\mathrm{UE}}^{\mathrm{CE} *}$ \\
\hline 0.1 & 0.1 & 0.1 & 1 & 0.133 & 0.071 & 0.366 & 0.367 & 0.267 \\
\hline 0.1 & 0.5 & 1 & 1 & 0.129 & .071 & .366 & 0.367 & 0.267 \\
\hline 0.1 & 1 & 1 & 1 & 24 & & 366 & 0.367 & 0.267 \\
\hline 0.1 & 4 & 0.056 & .563 & & & .381 & 0.338 & 0.281 \\
\hline 0.1 & 10 & 0.021 & 0.209 & 0.094 & & 0.393 & 0.314 & 0.293 \\
\hline 0.2 & 0.1 & 2 & 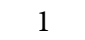 & 156 & & 0.4 & 0.4 & 0.2 \\
\hline 0.2 & 0.5 & & 1 & & & & .4 & 0.2 \\
\hline 0.2 & 1 & 0.2 & 1 & 0.12 & 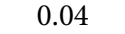 & 0.4 & 0.4 & 0.2 \\
\hline 0.2 & 4 & 0.05 & 0.25 & 0.08 & & 0.45 & 0.3 & 0.25 \\
\hline 0.2 & 10 & 0.019 & 0.093 & 0.074 & 0.068 & 0.461 & 0.279 & 0.26 \\
\hline .3 & 0.1 & & 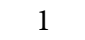 & & & .434 & 0.433 & 0.133 \\
\hline .3 & 0.5 & 0.3 & 1 & 3 & & .434 & 0.433 & 0.133 \\
\hline 0.3 & 1 & 0.28 & 0.933 & 98 & & 44 & 0.w42 & 0.14 \\
\hline 0.3 & 4 & 0.044 & 146 & 51 & & 518 & 0.263 & 0.219 \\
\hline & 10 & 0 & 054 & & & & 0.244 & .228 \\
\hline$t$ & 0.1 & & 1 & 0.202 & & 66 & 0.467 & 0.067 \\
\hline 0.4 & 0.5 & & 1 & & & 0.466 & 0.467 & 0.067 \\
\hline 0.4 & 1 & 24 & 0.6 & & & & 0.36 & 0.12 \\
\hline 0 & 4 & 0 & 04 & & & & 0.225 & 0.188 \\
\hline 1 & 10 & 0 & 35 & & & 96 & 0.209 & 0.195 \\
\hline 0. & 0.1 & & 1 & & & & 05 & 0 \\
\hline 0.5 & 0.5 & & 1 & & & & 0.5 & 0 \\
\hline 0 & 1 & & 1 & & & & 3 & 0 \\
\hline 0.5 & 4 & 31 & 063 & & & 56 & 0.188 & 0.156 \\
\hline 0.5 & 10 & 0.012 & 023 & & & & 0.174 & 0.163 \\
\hline 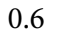 & 0.1 & & 1 & & & 467 & 0.533 & 0 \\
\hline 0.6 & 0.5 & & 1 & & & .467 & 0.533 & 0 \\
\hline 0.6 & 1 & 16 & 0.267 & 32 & 06 & 58 & 0.24 & 0.08 \\
\hline 0.6 & 4 & 0.025 & 0.042 & & & .725 & 0.15 & 0.125 \\
\hline 0.6 & 10 & 0.009 & 0.016 & & 0.017 & & 0.14 & 0.13 \\
\hline 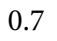 & 0.1 & & 1 & & 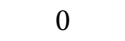 & 433 & 0.567 & 0 \\
\hline 0.7 & 0.5 & & 1 & & & 0.433 & 0.567 & 0 \\
\hline 0.7 & 1 & & & & & 0.76 & 0.18 & 0.06 \\
\hline 0. & 4 & 0.019 & 0.027 & & 9 & 0.793 & 0.113 & 0.094 \\
\hline 0 . & 10 & 0.007 & 0.01 & & 0.01 & 0.797 & 0.105 & 0.098 \\
\hline 0. & 0.1 & & 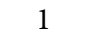 & & 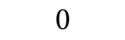 & & 0.6 & 0 \\
\hline 0.8 & 0.5 & & 1 & & . & 0.1 & 0.6 & 0 \\
\hline 0 . & 1 & 0.08 & 0.1 & 0.008 & 002 & 0.84 & 0.12 & 0.04 \\
\hline 0 & 4 & & & & & & 0.075 & 0.063 \\
\hline 0.8 & 10 & 0.005 & 0.006 & 0.005 & 0.0042 & 0.865 & 0.07 & 0.065 \\
\hline
\end{tabular}

$$
\left\{\begin{array}{l}
p_{\mathrm{LR}}^{\mathrm{CI} *}=1-\frac{\left(1-c+\Delta c_{\mathrm{LR}}^{C}\right)\left(2-\rho_{\mathrm{LR}}^{C}\right)}{3-\rho_{\mathrm{LR}}^{C}}, \\
E\left(\pi_{\mathrm{LR}}^{\mathrm{CI} *}\right)=\frac{\left(1-c+\Delta c_{\mathrm{LR}}^{C}\right)^{2}\left(2-\rho_{\mathrm{LR}}^{C}\right)}{\left(3-\rho_{\mathrm{LR}}^{C}\right)^{2}}+\rho_{\mathrm{LR}}^{C} R, \\
E\left(\pi_{\mathrm{LR}}^{\mathrm{CE} *}\right)=\frac{\left(1-c+\Delta c_{\mathrm{LR}}^{C}\right)^{2}}{\left(3-\rho_{\mathrm{LR}}^{C}\right)^{2}}-\rho_{\mathrm{LR}}^{C} R .
\end{array}\right.
$$

The profit function for Firm $I$ at the stage of $R \& D$ is $\pi_{\mathrm{LR}}^{R \& D}=\pi_{\mathrm{LR}}^{\mathrm{CI} *}-\theta\left(\Delta c_{\mathrm{LR}}^{C}\right)^{2}$. By substituting $\rho=\Delta c / c$ into this equation and solving it together with equation (17), we get the following equation:

$$
\pi_{\mathrm{LR}}^{R \& D}=\frac{c\left(1-c+\Delta c_{\mathrm{LR}}^{C}\right)^{2}\left(c-\Delta c_{\mathrm{LR}}^{C}\right)}{\left(3 c-\Delta c_{\mathrm{LR}}^{C}\right)^{2}}+\frac{\Delta c_{\mathrm{LR}}^{C}}{c} R-\theta\left(\Delta c_{\mathrm{LR}}^{C}\right)^{2} .
$$

Firm I's optimal R\&D investment level can be revealed by taking the first-order optimal condition of $\Delta c_{\mathrm{LR}}^{C}$ for $\pi_{\mathrm{LR}}^{R \& D}$. Because the functional form of the final result is rather complicated, it is difficult to observe the market outcome intuitively. To simplify analysis, the market outcome under the profit loss rule is calculated based on a numerical example. Considering that Firm I's profit obtained in both situations A and B can be regarded as its "due profit" under the assumption of this paper, both situations are analyzed in this paper. So, we need to analyze the both situations. For example, given $c=0.2$ and $\theta=4$, if the profit loss situation referred to by the court is situation $A$, it can be seen from Table 1 that $R=\pi^{\mathrm{AE} *}=(1-c)^{2} \theta / 9 \theta-4$. Substituting $c=$ $0.2, \theta=4$ and $R=0.08$ into equation (18) and taking the first-order optimal conditions of $\Delta c_{\mathrm{LR}}^{C}$ for $\pi_{\mathrm{LR}}^{R \& D}$, the optimal innovation height and patent quality of Firm I can be derived as $\Delta c_{\mathrm{LR}}^{C *}=0.23$. Then, the optimal profit of each firm can be obtained by combining these calculation results and formula (16). Similarly, if the profit loss situation referred to by the court is situation $\mathrm{B}$, given that $c=0.02$ and $\theta=4$, from Table 1 and equation (12), we can calculate that $R=\pi^{\mathrm{BE} *}=0.091$. The optimal invention height and profit of firm I can be derived from combining $R=0.091$ and equation (18). The detailed results are shown in Tables 3 and 4 .

\section{Comparison and Optimization}

5.1. Comparison of Innovation Incentives in Different Situations. According to the preceding analysis results, numerical examples can be obtained for patent quality in different situations, as shown by Table 3 (profit loss rule A means that the court refers to the profit loss in situation $\mathrm{A}$ when adopting the profit loss rule, while profit loss rule $\mathrm{B}$ means that the court refers to the profit loss in situation $B$ when adopting the profit loss rule). As shown by the comparison of patent quality among the five situations in Table 3, the patent quality in none of the situations can always be maintained at the highest level. In the case of noninfringement, except $\rho^{A} \geq \rho^{B}$ when $\theta=1$, the patent quality in situation $A$ will never be better than that in situation $B$ under other conditions. This is because situation $\mathrm{A}$ is a competitive market, while situation $\mathrm{B}$ is a monopolistic market. Different market structures have different incentive effects on firms. In the competitive market, Firm I innovates in order to gain a competitive edge. This reflects the incentive effects of competition on innovation. In the monopolistic market, Firm I innovates in order to cut down the costs for greater profit. This reflects the incentive effects of monopoly on innovation. When $\theta=1$, competition has greater incentive effects on innovation, so the patent quality in situation A is higher; under other conditions, the monopoly has greater incentive effects on innovation, so the patent quality in situation $B$ is higher. 
TABLE 3: Numerical examples of patent quality in different situations.

\begin{tabular}{|c|c|c|c|c|c|c|}
\hline$c$ & $\theta$ & $\rho^{A}$ & $\rho^{B}$ & $\rho_{\mathrm{UE}}^{C}$ & $\rho_{\mathrm{LR}}^{C}($ profit loss rule $\mathrm{A})$ & $\rho_{\mathrm{LR}}^{C}$ (profit loss rule $\left.\mathrm{B}\right)$ \\
\hline 0.1 & 0.1 & 1 & 1 & 1 & 0.74 & 0.85 \\
\hline 0.1 & 0.5 & 1 & 1 & 1 & 0.71 & 0.83 \\
\hline 0.1 & 1 & 1 & 1 & 1 & 0.67 & 0.8 \\
\hline 0.1 & 4 & 0.563 & 0.6 & 1 & 0.46 & 0.59 \\
\hline 0.1 & 10 & 0.209 & 0.231 & 1 & 0.31 & 0.37 \\
\hline 0.2 & 0.1 & 1 & 1 & 1 & 0.84 & 0.92 \\
\hline 0.2 & 0.5 & 1 & 1 & 1 & 0.77 & 0.84 \\
\hline 0.2 & 1 & 1 & 1 & 1 & 0.7 & 0.73 \\
\hline 0.2 & 4 & 0.25 & 0.267 & 1 & 0.23 & 0.29 \\
\hline 0.2 & 10 & 0.093 & 0.103 & 0.12 & 0.1 & 0.125 \\
\hline 0.3 & 0.1 & 1 & 1 & 1 & 0.87 & 0.94 \\
\hline 0.3 & 0.5 & 1 & 1 & 1 & 0.69 & 0.78 \\
\hline 0.3 & 1 & 0.933 & 0.778 & 1 & 0.447 & 0.56 \\
\hline 0.3 & 4 & 0.146 & 0.156 & 0.14 & 0.117 & 0.143 \\
\hline 0.3 & 10 & 0.054 & 0.06 & 0.05 & 0.047 & 0.057 \\
\hline 0.4 & 0.1 & 1 & 1 & 1 & 0.903 & 0.94 \\
\hline 0.4 & 0.5 & 1 & 1 & 1 & 0.615 & 0.673 \\
\hline 0.4 & 1 & 0.6 & 0.5 & 1 & 0.293 & 0.37 \\
\hline 0.4 & 4 & 0.094 & 0.1 & 0.07 & 0.065 & 0.078 \\
\hline 0.4 & 10 & 0.035 & 0.038 & 0.025 & 0.025 & 0.03 \\
\hline 0.5 & 0.1 & 1 & 1 & 1 & 0.92 & 0.92 \\
\hline 0.5 & 0.5 & 1 & 1 & 1 & 0.514 & 0.514 \\
\hline 0.5 & 1 & 0.4 & 0.333 & 0.232 & 0.184 & 0.226 \\
\hline 0.5 & 4 & 0.063 & 0.067 & 0.04 & 0.038 & 0.044 \\
\hline 0.5 & 10 & 0.023 & 0.026 & 0.016 & 0.016 & 0.016 \\
\hline 0.6 & 0.1 & 1 & 1 & 1 & 0.93 & 0.892 \\
\hline 0.6 & 0.5 & 0.667 & 0.667 & 1 & 0.392 & 0.338 \\
\hline 0.6 & 1 & 0.267 & 0.222 & 0.122 & 0.113 & 0.135 \\
\hline 0.6 & 4 & 0.042 & 0.044 & 0.023 & 0.023 & 0.027 \\
\hline 0.6 & 10 & 0.016 & 0.017 & 0.01 & 0.01 & 0.01 \\
\hline 0.7 & 0.1 & 1 & 1 & 1 & 0.936 & 0.861 \\
\hline 0.7 & 0.5 & 0.429 & 0.429 & 0.193 & 0.261 & 0.199 \\
\hline 0.7 & 1 & 0.171 & 0.143 & 0.067 & 0.067 & 0.076 \\
\hline 0.7 & 4 & 0.027 & 0.029 & 0.014 & 0.014 & 0.016 \\
\hline 0.7 & 10 & 0.01 & 0.011 & 0.006 & 0.006 & 0.006 \\
\hline 0.8 & 0.1 & 1 & 1 & 1 & 0.936 & 0.825 \\
\hline 0.8 & 0.5 & 0.25 & 0.25 & 0.09 & 0.136 & 0.101 \\
\hline 0.8 & 1 & 0.1 & 0.083 & 0.035 & 0.036 & 0.039 \\
\hline 0.8 & 4 & 0.016 & 0.017 & 0.0075 & 0.008 & 0.009 \\
\hline 0.8 & 10 & 0.006 & 0.006 & 0.0025 & 0.003 & 0.004 \\
\hline
\end{tabular}

In the case of infringement, the patent quality under the unjust enrichment rule is generally better than that of the profit loss rule. If it is for the purpose of improving patent quality, the profit loss rule may not be a good choice. This is because Firm I will not provide a full-quality patent in whichever situation a profit loss occurs. In particular, under profit loss rule $\mathrm{A}$, the patent quality is at a suboptimal level no matter the condition. This is because the amount of infringement compensation under profit loss rule $\mathrm{A}$ is lower than that under profit loss rule $\mathrm{B}$, so the latter has better incentive effects on innovation. However, neither situation performs better than other two situations. For example, situation $B$ is better than other two situations only when $c=0.2$ and $\theta=10$. Therefore, the profit loss rule has a very limited effect in improving patent quality. Subsequently, Proposition 3 can be proposed as follows.
Proposition 3. In the case of non-infringement, the patent quality in situation $B$ is better than that in situation $A$ under most circumstances. In the case of infringement, if the court prefers the profit loss rule, Firm I will not provide a full-quality patent in any situation where a profit loss occurs. Compared with the profit loss rule, the unjust enrichment rule can obtain better patent quality under most circumstances.

5.2. Subgame Perfect Nash Equilibrium (SPNE). We adopt the reverse induction method to analyze SPNE. First, Firm I's decision at the final stage of the game is analyzed. Based on the previous analysis, numerical examples can be obtained for firm's final profit gained in different situations, as shown in Table 4. 
TABLE 4: Numerical examples of Firm E's profit in different situations.

\begin{tabular}{|c|c|c|c|c|c|c|}
\hline$c$ & $\theta$ & $\pi^{\mathrm{AE} *}$ & $\pi^{\mathrm{BE} *}$ & $E\left(\pi_{\mathrm{UE}}^{\mathrm{CE} *}\right)$ & $E\left(\pi_{\mathrm{LR}}^{\mathrm{CE} *}\right)$ (profit loss rule $\left.\mathrm{A}\right)$ & $E\left(\pi_{\mathrm{LR}}^{\mathrm{CE} *}\right)$ (profit loss rule $\left.\mathrm{B}\right)$ \\
\hline 0.1 & 0.1 & 0.071 & 0.071 & 0 & 0.087 & 0.059 \\
\hline 0.1 & 0.5 & 0.071 & 0.071 & 0 & 0.088 & 0.061 \\
\hline 0.1 & 1 & 0.071 & 0.071 & 0 & 0.089 & 0.063 \\
\hline 0.1 & 4 & 0.079 & 0.079 & 0 & 0.092 & 0.078 \\
\hline 0.1 & 10 & 0.086 & 0.086 & 0 & 0.089 & 0.082 \\
\hline 0.2 & 0.1 & 0.04 & 0.04 & 0 & 0.068 & 0.034 \\
\hline 0.2 & 0.5 & 0.04 & 0.04 & 0 & 0.062 & 0.041 \\
\hline 0.2 & 1 & 0.04 & 0.04 & 0 & 0.057 & 0.05 \\
\hline 0.2 & 4 & 0.063 & 0.063 & 0 & 0.075 & 0.069 \\
\hline 0.2 & 10 & 0.068 & 0.068 & 0.072 & 0.072 & 0.07 \\
\hline 0.3 & 0.1 & 0.018 & 0.018 & 0 & 0.048 & 0.017 \\
\hline 0.3 & 0.5 & 0.018 & 0.018 & 0 & 0.056 & 0.031 \\
\hline 0.3 & 1 & 0.02 & 0.02 & 0 & 0.063 & 0.046 \\
\hline 0.3 & 4 & 0.048 & 0.048 & 0.058 & 0.058 & 0.056 \\
\hline 0.3 & 10 & 0.052 & 0.052 & 0.056 & 0.056 & 0.055 \\
\hline 0.4 & 0.1 & 0.004 & 0.004 & 0 & 0.028 & 0.009 \\
\hline 0.4 & 0.5 & 0.004 & 0.004 & 0 & 0.041 & 0.028 \\
\hline 0.4 & 1 & 0.014 & 0.014 & 0 & 0.049 & 0.042 \\
\hline 0.4 & 4 & 0.035 & 0.035 & 0.043 & 0.043 & 0.042 \\
\hline 0.4 & 10 & 0.038 & 0.038 & 0.041 & 0.041 & 0.041 \\
\hline 0.5 & 0.1 & 0 & 0 & 0 & 0.006 & 0.006 \\
\hline 0.5 & 0.5 & 0 & 0 & 0 & 0.028 & 0.028 \\
\hline 0.5 & 1 & 0.01 & 0.01 & 0.038 & 0.035 & 0.032 \\
\hline 0.5 & 4 & 0.024 & 0.024 & 0.03 & 0.0295 & 0.0293 \\
\hline 0.5 & 10 & 0.027 & 0.027 & 0.029 & 0.0285 & 0.0284 \\
\hline 0.6 & 0.1 & 0 & 0 & 0 & 0.006 & 0.006 \\
\hline 0.6 & 0.5 & 0 & 0 & 0 & 0.024 & 0.024 \\
\hline 0.6 & 1 & 0.006 & 0.006 & 0.024 & 0.023 & 0.022 \\
\hline 0.6 & 4 & 0.016 & 0.016 & 0.019 & 0.0188 & 0.0189 \\
\hline 0.6 & 10 & 0.017 & 0.017 & 0.018 & 0.0183 & 0.0182 \\
\hline 0.7 & 0.1 & 0 & 0 & 0 & 0.005 & 0.005 \\
\hline 0.7 & 0.5 & 0 & 0 & 0.019 & 0.011 & 0.016 \\
\hline 0.7 & 1 & 0.004 & 0.004 & 0.013 & 0.013 & 0.013 \\
\hline 0.7 & 4 & 0.009 & 0.009 & 0.011 & 0.011 & 0.011 \\
\hline 0.7 & 10 & 0.01 & 0.009 & 0.01 & 0.01 & 0.01 \\
\hline 0.8 & 0.1 & 0 & 0 & 0 & 0.003 & 0.003 \\
\hline 0.8 & 0.5 & 0 & 0 & 0.008 & 0.0073 & 0.0073 \\
\hline 0.8 & 1 & 0.002 & 0.002 & 0.006 & 0.006 & 0.006 \\
\hline 0.8 & 4 & 0.0039 & 0.0039 & 0.0047 & 0.005 & 0.0047 \\
\hline 0.8 & 10 & 0.0042 & 0.0042 & 0.0045 & 0.005 & 0.0046 \\
\hline
\end{tabular}

Proposition 4 can be put forth by comparing Firm E's profit in the five situations in Table 4.

\section{Proposition 4}

(1) If the court prefers the unjust enrichment rule, equilibrium results will appear on the market as the original marginal cost and R\&D efficiency change. If the original marginal cost is extremely low, e.g., $c<0.1$, Firm E will accept the patent license contract from Firm I as the only SPNE, no matter what R\&D efficiency is; as the original marginal cost increases and R\&D efficiency decreases, e.g., $c \geq 0.5$ and $\theta>1$, Firm $E$ will carry out production by means of infringement as the only SPNE.

(2) If the court prefers profit loss rule A, there exists the only SPNE, i.e., Firm E carries out production by means of infringement. If the court prefers profit loss rule $B$ and the original marginal cost is very low, e.g., $c<0$.1, Firm $E$ will accept the patent license contract from Firm I as the only SPNE no matter what R\&D efficiency is; as the original marginal cost increases and R\&D efficiency decreases, e.g., $c \geq 0.2$ and $\theta>1$, Firm $E$ will be increasingly motivated to infringe patent rights. When the original marginal cost is high, i.e.,c $\geq 0.4$, Firm E will carry out production by means of infringement as the only SPNE no matter what R\&D efficiency is.

According to Proposition 4, compared with profit loss rule $B$, Firm E will be more likely to carry out production by means of infringement under profit loss rule $A$. The reason is that under profit loss rule A, Firm I's profit loss is confirmed by reference to the competitive profit, but under profit loss rule $B$, the firm's profit loss is confirmed by reference to the monopoly profit. Therefore, when Firm E is found guilty of infringement, if the court adopts profit loss rule A, Firm E will only need to 
pay a small amount as compensation; on the contrary, if the court adopts profit loss rule $B$, firm $E$ will have to pay a large amount as compensation. Therefore, Firm $E$ has a stronger motive for infringement under profit loss rule $A$.

5.3. Optimization of the Patent System. As can be seen from Table 3 , in the case of non-infringement, the patent quality in situation B is better than that in situation A under most circumstances, so the court should promote conditions leading to situation B. Therefore, it should not interfere with Firm I's patent licensing act but let Firm I exercise its patent right to monopolize the market for further innovation.

In the case of infringement, if the court prefers the unjust enrichment rule, as shown by the comparison between $\pi^{\mathrm{BE} *}$ and $E\left(\pi_{\mathrm{UE}}^{\mathrm{CE} *}\right)$, when it is easy to innovate (the R\&D efficiency is high, or the original marginal cost is low, or both), e.g., the ultimate market equilibrium is also achieved in situation B, and Firm I can provide a high-quality patent. When it is difficult to innovate (the R\&D efficiency is low, or original marginal cost is high, or both), e.g., when $\theta=10$ and $c \geq 0.2$, $\pi^{\mathrm{BE} *} \leq E\left(\pi_{\mathrm{UE}}^{\mathrm{CE} *}\right)$. The ultimate market equilibrium is achieved in situation $C$.

As is noted, when it is difficult to innovate, under profit loss rule $\mathrm{B}, \rho_{\mathrm{LR}}^{\mathrm{C}} \geq \rho_{\mathrm{UE}}^{\mathrm{C}}$ and $E\left(\pi_{\mathrm{LR}}^{\mathrm{CE} *}\right) \geq \pi^{\mathrm{BE} *}$. If the court adopts profit loss rule $\mathrm{B}$ at this time, the ultimate equilibrium is achieved in situation C, but better patent quality is ensured (it is also difficult to achieve good results if profit loss rule $\mathrm{B}$ is used alone because when it is easy to innovate, the rule has very limited effect in improving patent quality; for example, when $\theta=0.1$ and $c=0.4$, the ultimate market equilibrium is achieved in situation $\mathrm{C}$ under profit loss rule $\mathrm{B}$, and patent quality is 0.94 ; the ultimate market equilibrium is achieved in situation $\mathrm{A}$ under the unjust enrichment rule, and patent quality is 1 ). Therefore, when it is easy to innovate, the court should give priority to the unjust enrichment rule and achieve the ultimate market equilibrium of situation B; when it is difficult to innovate, the court should give priority to the profit loss rule to achieve the ultimate market equilibrium of situation $\mathrm{C}$, so as to ultimately improve patent quality effectively.

When it is difficult to innovate, the court should give priority to profit loss rule $\mathrm{B}$ to achieve the ultimate market equilibrium of situation $\mathrm{C}$ so as to ultimately achieve effective patent quality optimization. If the court aims to optimize patent quality, it may be difficult to achieve ideal results under a single patent infringement compensation rule. The court needs to adopt different compensation rules for different situations. Concretely speaking, when it is easy to innovate, the unjust enrichment rule should be adopted first; when it is difficult to innovate, profit loss rule B should be adopted first.

\section{Conclusions}

The original intention of designing a patent system is to help innovators to obtain returns by commercializing their inventions, thus recovering their $\mathrm{R} \& \mathrm{D}$ costs and maintaining their motivation for innovation. However, the presence of "questionable patents" is obviously contrary to this original intention. A large number of low-quality patents have exerted great negative impacts on the normal operation of the patent systems. An endogenous model of patent quality was built in this paper to investigate the effects of different patent infringement compensation rules on patent quality.

The main conclusions are represented as the following three aspects. Firstly, in whatever situation, an innovative firm is likely to provide a questionable patent due to the strict requirements for a high-level innovation height or low $\mathrm{R} \& \mathrm{D}$ efficiency, compelling the innovative firm to bear a high investment cost if it wants to provide a full-quality patent. At this time, the profits brought by innovation cannot fully cover the R\&D cost, leading the innovative firm to provide a "questionable patent." Therefore, the presence of "questionable patents" may not only be due to innovators' speculative behavior but also be due to the effects of specific market conditions on the innovators under many circumstances. Secondly, in the case of non-infringement, although the innovation incentives for an innovative firm are greater in the monopolistic market than in the competitive market, it can provide a higher-quality patent in the competitive market under certain conditions. In the case of infringement, the patent quality under the unjust enrichment rule is generally better than that under the profit loss rule. However, when it is very difficult to innovate, profit loss rule B can better motivate an innovative firm to innovate. Thirdly, if the court adopts a single patent infringement compensation rule, it will be difficult to optimize patent quality. Owing to the differences in their operating mechanism, different patent infringement compensation rules differ from one another in terms of innovation incentives for inventors. To improve patent quality, the court needs to adopt the correct patent infringement compensation rule depending on the circumstances. For example, when it is easier to innovate, the unjust enrichment rule should be adopted first; when it is difficult to innovate, the profit loss rule should be adopted first. Moreover, profit loss needs to reference the profit gained by the innovator under monopoly conditions.

It should be noted that this research can be expanded along different directions, which deserves further investigation. We consider the Cournot competition between different firms. If we further consider Bertrand competition between the firms, the conclusions may be different. Moreover, the research object of this innovation is costcutting innovation. If the research object is product innovation or quality ladder innovation, different conclusions may be drawn. It is worth mentioning that machine learning may be powerful in solving patent-related problems. As an emerging discipline, machine learning is a subfield of computer science that evolved from the study of pattern recognition and computational learning theory in artificial intelligence [22-24] and explores the study and construction of algorithms that can learn from and make predictions for complicated scenarios. If machine learning is applied to the process of patent examination, it may make the patent system more intelligent and efficient. At the same time, it can also increase the accuracy of patent examination results and help improve the patent quality greatly (Burk and Lemley [8] argued that "various inventions and innovations are totally 
different in nature; the difference in industry finds expression in the form of inventions and innovations; accordingly, there is a difference in patenting process").

\section{Data Availability}

All the data has been included in the manuscript.

\section{Conflicts of Interest}

The authors declare that they have no conflicts of interest.

\section{References}

[1] J. Haejun, "Patent infringement, litigation, and settlement," Economic Modelling, vol. 51, pp. 99-111, 2015.

[2] M. A. Lemley and C. Shapiro, "Probabilistic patents," Journal of Economic Perspectives, vol. 19, no. 2, pp. 75-98, 2005.

[3] J. P. Choi, "Alternative damage rules and probabilistic intellectual property rights: unjust enrichment, lost profits, and reasonable royalty remedies," Information Economics and Policy, vol. 21, no. 2, pp. 145-157, 2009.

[4] A. Nuvolari, "Collective invention during the british industrial revolution: the case of the Cornish pumping engine," Cambridge Journal of Economics, vol. 28, no. 3, pp. 347-363, 2004.

[5] S. K. Sell, Private Power, Public Law: The Globalization of Intellectual Property Rights, Cambridge University Press, Cambridge, UK, 2003.

[6] L. Cohen, U. G. Gurun, and S. D. Kominers, "Patent trolls: evidence from targeted firms," Management Science, vol. 65, no. 12, pp. 5461-5486, 2019.

[7] R. Amir, D. Encaoua, and Y. Lefouili, "Optimal licensing of uncertain patents in the shadow of litigation," Games and Economic Behavior, vol. 88, pp. 320-338, 2014.

[8] D. L. Burk and M. A. Lemley, The Patent Crisis and How the Courts Can Solve it, University of Chicago Press, Chicago, IL, USA, 2009.

[9] J. P. Choi, "Live and let live: a tale of weak patents," Journal of the European Economic Association, vol. 3, no. 2-3, pp. 724-733, 2005.

[10] J. Farrell and C. Shapiro, "How strong are weak patents?" American Economic Review, vol. 98, no. 4, pp. 1347-1369, 2008.

[11] D. Encaoua and Y. Lefouili, "Licensing 'weak' patents," The Journal of Industrial Economics, vol. 57, no. 3, pp. 492-525, 2009.

[12] F. Schuett, "Patent quality and incentives at the patent office," The RAND Journal of Economics, vol. 44, no. 2, pp. 313-336, 2013.

[13] S. Kwon, "The prevalence of weak patents in the United States: a new method to identify weak patents and the implications for patent policy," Technology in Society, vol. 64, Article ID 101469, 2021.

[14] D. Teece, E. Sherry, and P. Grindley, "Patents and 'patent wars' in wireless communications: an economic assessment," Communications \& Strategies, no. 95, p. 85, 2014.

[15] B. J. Love, “To improve patent quality, let's use fees to weed out weak patents," Berkeley Technology Law Journal.

[16] Z. Lei and B. D. Wright, "Why weak patents? testing the examiner ignorance hypothesis," Journal of Public Economics, vol. 148, pp. 43-56, 2017.
[17] J. P. Choi and H. Gerlach, "Patent pools, litigation, and innovation," The RAND Journal of Economics, vol. 46, no. 3, pp. 499-523, 2015.

[18] M. J. Mazzeo, J. Hillel, and S. Zyontz, "Explaining the "unpredictable": an empirical analysis of U.S. patent infringement awards," International Review of Law and Economics, vol. 35, pp. 58-72, 2013.

[19] P. Pincus, "Colloid stabilization with grafted polyelectrolytes," Macromolecules, vol. 24, no. 10, pp. 2912-2919, 1991.

[20] J. A. Tessensohn, "Patent infringement royalty rate boosted by grand panel ip high court of Japan," European Intellectual Property Review, vol. 42, no. 5, pp. 320-322, 2020.

[21] Y. Zhang and M. Guizani, Game Theory for Wireless Communications and Networking, CRC Press, Boca Raton, FL, USA, 2011.

[22] C. Lee, O. Kwon, M. Kim, and D. Kwon, "Early identification of emerging technologies: a machine learning approach using multiple patent indicators," Technological Forecasting and Social Change, vol. 127, pp. 291-303, 2018.

[23] J. Choi, B. Jeong, J. Yoon, B.-Y. Coh, and J.-M. Lee, "A novel approach to evaluating the business potential of intellectual properties: a machine learning-based predictive analysis of patent lifetime," Computers \& Industrial Engineering, vol. 145, p. 106544, 2020.

[24] X.-L. Huang, X. Ma, and F. Hu, "Editorial: machine learning and intelligent communications," Mobile Networks and Applications, vol. 23, no. 1, pp. 68-70, 2018. 